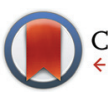

CrossMark $\leftarrow$ click for updates

Cite this: Dalton Trans., 2016, 45 15811

Received 9th May 2016,

Accepted 15th June 2016

DOI: $10.1039 / c 6 d t 01823 h$

www.rsc.org/dalton

\title{
The influence of the ligand chelate effect on iron-amine-catalysed Kumada cross-coupling $\dagger$
}

\author{
Robin B. Bedford, ${ }^{\text {*a }}$ Peter B. Brenner, ${ }^{a}$ David Elorriaga, ${ }^{a}$ Jeremy N. Harvey ${ }^{\mathrm{b}}$ and \\ Joshua Nunn ${ }^{a}$
}

\begin{abstract}
The application of a variety of iron complexes with chelating amine ligands as pre-catalysts in the representative cross-coupling of 4-tolylmagnesium bromide with cyclohexyl bromide was investigated. The results from this study indicate the performance of the pre-catalyst is inversely proportional to the strength of the chelate or macrocyclic effect of the amine ligand, as determined by the propensity of the ligand to be displaced from the iron centre by reaction with excess benzyl magnesium chloride. The findings from this study are consistent with a catalytic cycle wherein the chelating amine ligand is not coordinated to the iron centre during turnover.
\end{abstract}

\section{Introduction}

While there is no doubt that palladium-catalysed cross-coupling is an exceptionally powerful synthetic methodology (Scheme 1(a)), ${ }^{1}$ the benefits of the use of palladium are offset by its high price, relative toxicity and the environmental impact of its extraction. ${ }^{2}$ Accordingly there has been much recent $^{3}$ effort expended on developing iron-based catalysts for cross-couplings, ${ }^{4}$ due to the far lower cost, toxicity and supply issues associated with iron. By far the most widely studied iron-catalysed cross-coupling reaction is the Kumada reaction, that is the coupling of Grignard reagents with alkyl or aryl halides and related electrophilic substrates (Scheme 1(b)). ${ }^{4}$

(a)

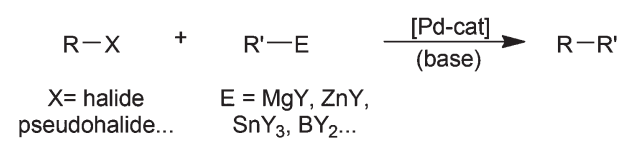

(b)

$$
\mathrm{R}-\mathrm{X}+\mathrm{R}-\mathrm{MgX} \stackrel{[\mathrm{Fe}-\mathrm{cat}]}{\longrightarrow} \mathrm{R}-\mathrm{R}^{\prime}
$$

Scheme 1 (a) Generalised palladium-catalysed cross-coupling; (b) the iron-catalysed Kumada reaction.

\footnotetext{
${ }^{a}$ School of Chemistry, University of Bristol, Cantock's Close, Bristol, BS8 1TS, UK. E-mail: r.bedford@bristol.ac.uk

${ }^{b}$ Quantum Chemistry and Physical Chemistry Section, Department of Chemistry, University of Leuven (KU Leuven), Celestijnenlaan $200 F$ - box 2404, Leuven, Belgium $\dagger$ Electronic supplementary information (ESI) available: Crystallographic experimental and data. CCDC 1478297 and 1478298. For ESI and crystallographic data in CIF or other electronic format see DOI: 10.1039/c6dt01823h
}

While several classes of complexes and ligands have been investigated, amine complexes of iron have been found to be particularly useful pre-catalysts in a range of iron-catalysed Kumada reactions, often giving high yields and good selectivity for the cross-coupled product. For instance Nakamura and Nakamura showed that 1,2-bis(dimethylamino)ethane, TMEDA, could be employed to good effect, providing that it was used in stoichiometric or greater amounts with respect to the Grignard substrate and that the amine-Grignard mixture was added slowly to the reaction mixture, typically with a syringe pump. ${ }^{5}$ We, ${ }^{6}$ and subsequently Cahiez, ${ }^{7}$ demonstrated that TMEDA, as well as other amine ligands, could actually be used in catalytic quantities and that slow addition was not always required for good activity.

Clearly, given the successes enjoyed with TMEDA and other chelating amines, it is important to establish the role(s) played by the ligands in the catalytic cycle of the iron-catalysed Kumada reaction. In the first study to address this issue, Nagashima and co-workers investigated the reaction of 3 equivalents of mesitylMgBr with $\mathrm{FeCl}_{3}$ and excess TMEDA. ${ }^{8}$ They showed that this gave the bis-mesityl complex $\mathbf{1}$, which reacts with octyl bromide to give the cross-coupled product and the second mesityl complex 2. Reaction of 2 with the Grignard reagent regenerates $\mathbf{1}$. On the basis of these observations, the authors proposed the catalytic cycle outlined in Scheme 2.

By contrast, we demonstrated that in the presence of excess $\mathrm{MesMgBr}$, such as would be seen under catalytic conditions, complex 1 reacts to generate the homoleptic 'ate' complex 3 (Scheme 3). ${ }^{9}$ Indeed ${ }^{1} \mathrm{H}$ NMR studies revealed that during catalysis only complex 3 is observed and not complex $\mathbf{1}$. Furthermore, complex 3 reacts far faster than complex 1 with OctBr, effectively eliminating $\mathbf{1}$ as a feasible catalytic intermediate in the primary cycle. We instead proposed the cycle shown in 


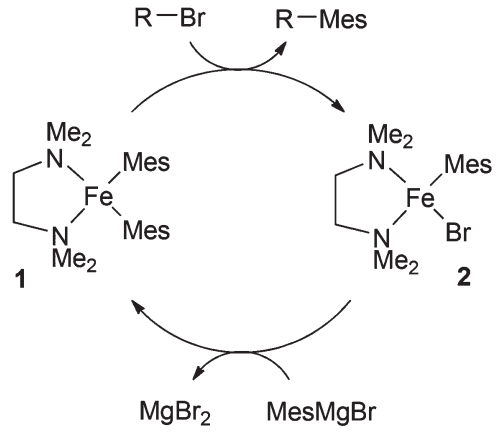

Scheme 2 Nagashima's proposed catalytic cycle. ${ }^{8}$

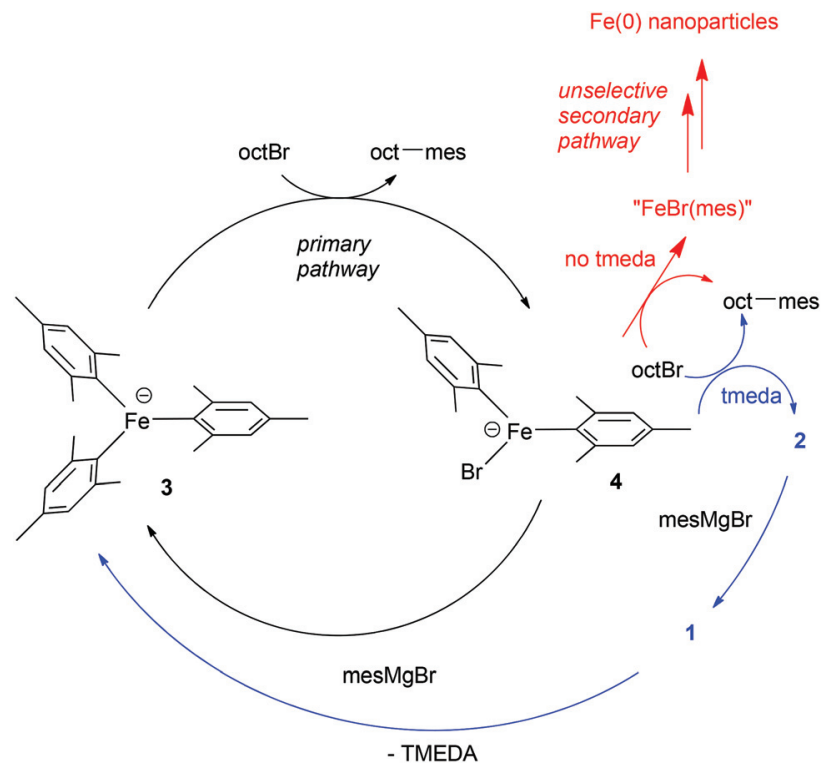

Scheme 3 Alternative catalytic pathway. ${ }^{10}$

Scheme $3,{ }^{10}$ based on the observations above and the finding that the same amount of cross-coupled product is generated in the absence of TMEDA, but that slightly increased amounts of side-products are obtained, suggesting a competing, non-selective pathway, possibly involving iron nanoparticles. ${ }^{9}$ In this proposed pathway, the amine ligand is not involved in the primary catalytic cycle, but rather it intercepts the thermally fragile intermediates derived from the reaction of the intermediate 4 with the electrophilic coupling partner, generating 2 before further decomposition can occur. Subsequent reaction of $\mathbf{2}$ with excess MesMgBr regenerates $\mathbf{3}$ via the intermediate $\mathbf{1}$.

Ultimately, these model studies are limited because mesityl Grignard is a poor, non-representative substrate in iron-catalysed cross-couplings, with low yields of the cross-coupled product furnished after protracted reaction times. ${ }^{8,9}$ Accordingly, we decided to investigate the effect of varying the aminedonor ligands in the presence of a smaller, far more representative aryl nucleophile. Clearly, if the mechanism in Scheme 3 is still operative with less bulky Grignard reagents, and the amine is required to dissociate from the iron centre in order for catalysis to proceed, then there should be an inverse dependence of catalytic activity on chelate complex stability. The results from this study support this hypothesis and are presented below.

\section{Results and discussion}

\section{Iron-amine chelate complexes}

The chelating amine complexes selected for study are shown in Fig. 1. Leigh and co-workers showed that the TMEDA adducts 5 and 6 both form in the reaction of TMEDA with $\mathrm{FeCl}_{2}$, crystallising at different rates. ${ }^{11}$ Therefore while we isolated the complex 6, in the catalytic studies (see below) mixtures of TMEDA: $\mathrm{FeCl}_{2}$ were used instead. The previously reported complex 7 contains the diamine ligand (-)-sparteine. ${ }^{12}$ The cage-like structure of sparteine gives much higher conformational rigidity compared with TMEDA, which in turn should lead to higher chelate complex stability. The tetradentate ligand in complex 8, HMTETA, should also give more stable iron complexes than those containing TMEDA, due to the higher denticity of the ligand. Complex $\mathbf{8}$ was prepared by reaction of HMTETA with $\mathrm{FeCl}_{2}$ in THF at reflux temperature for 8 hours, and the single crystal X-ray structure of the complex is shown in Fig. 2. As can be seen, the complex adopts a cis coordination geometry, in contrast to the TMEDA complex 5.

In order to increase complex stability further, the tetramethylcyclam (TMC)-containing complex 9 was prepared by warming the ligand with $\mathrm{FeCl}_{2}$ in acetonitrile at $40{ }^{\circ} \mathrm{C}$ for 90 minutes. The macrocyclic nature of the TMC ligand should confer higher stability of resultant complexes compared with the acyclic HMTETA. The crystal structure of $\mathbf{9}$ (Fig. 2) revealed a five-coordinate cationic complex, with chloride counter ion, in which the TMC ligand occupies both axial coordination sites and two of the equatorial ones, with the third equatorial position occupied by chloride.

Finally, the previously reported complex 10 was examined, ${ }^{13}$ which contains an ethylene-bridged cyclam ligand $\left(\mathrm{Me}_{2} \mathrm{EBC}\right)$.
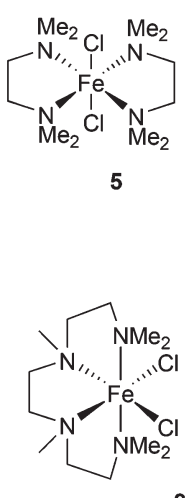

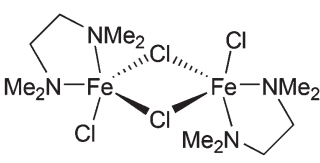

6

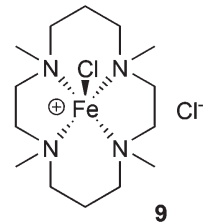

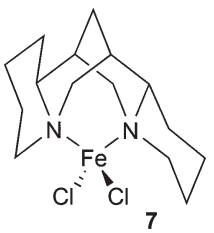

Fig. 1 The iron complexes examined. 



Fig. 2 X-ray crystal structures of complexes 8 and $\mathbf{9}$. Thermal ellipsoids set at 50\% probability; hydrogen atoms, chloride counter-ion of 9 and three molecules of $\mathrm{MeCN}$ solvate in 9 omitted for clarity.

In this case the bicyclic nature of the ligand would be expected to confer even greater macrocylic stabilisation, compared with the TMC ligand, giving by far the most stable complex of the series.

\section{Catalytic studies}

The complexes 7-10, as well as the species formed in situ from $\mathrm{FeCl}_{2}$ and TMEDA in THF were tested as pre-catalysts in the representative cross-coupling of 4-tolyl magnesium bromide with cyclohexylbromide, under two sets of conditions. In the first set of (A), the reaction was performed at $0{ }^{\circ} \mathrm{C}$ with slow addition of the Grignard reagent using a syringe pump, conditions similar to those reported by Nakamura. ${ }^{5}$ Meanwhile in the second set of conditions (B) the Grignard reagent was added rapidly and the reaction was warmed to $40{ }^{\circ} \mathrm{C}$, to mirror the conditions that we previously exploited. ${ }^{6}$ The results from this study are summarised in Table 1.

Compared with the excellent and good conversions observed after 1 hour with the TMEDA-containing system under slow and rapid addition of the Grignard reagent respectively (entries 1 and 2) it is clear that much lower activity is seen with the pre-catalyst 7 , which contains the more conformationally rigid diamine ligand sparteine (entries 3 and 4). Even worse activity is observed with complex 8, which contains the tetradentate chelating ligand HMTETA, under slow addition conditions (entry 5). Interestingly some activity is recovered when the reaction was repeated with rapid addition of the Grignard reagent.

In all the examples above, the catalysis is accompanied by the formation of black, heterogeneous reaction mixtures, most likely due to the formation of iron nanoparticles, which have previously been demonstrated to be catalytically competent in Kumada $^{14}$ and related cross-coupling reactions. ${ }^{15}$ By contrast, the reactions catalysed by complexes $\mathbf{9}$ or $\mathbf{1 0}$ remained homogeneous over the course of the reactions under both sets of conditions, and in all cases gave very little of the cross-coupled product 11. It is clear that an increase in the chelate or macrocyclic complex stability leads to a sharp decrease in catalyst
Table 1 Iron-catalysed Kumada cross-coupling

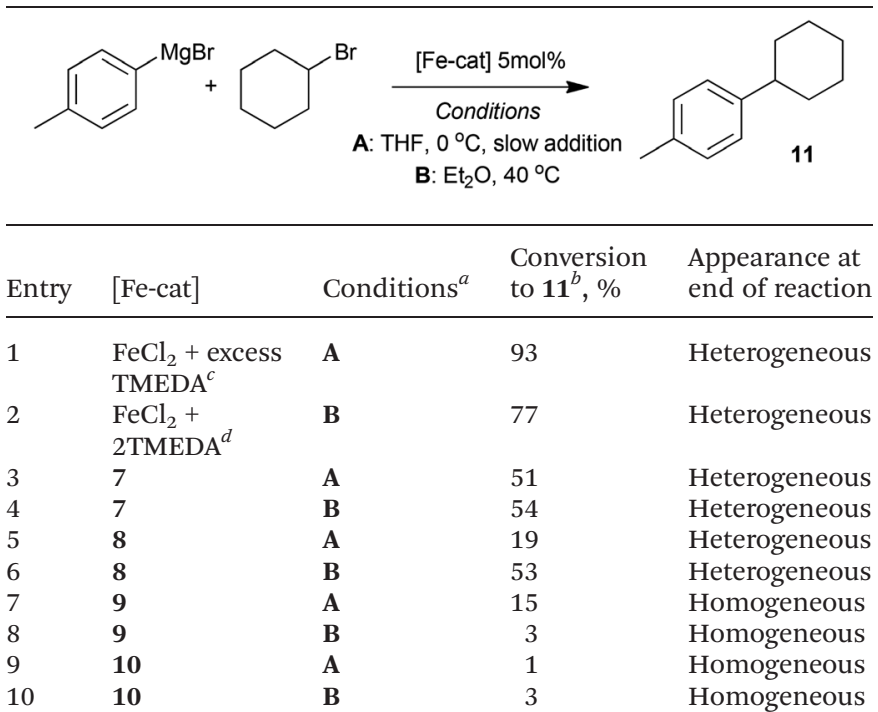

${ }^{a}$ Conditions, A: CyBr (1.0 mmol), 4-tolylMgBr (drop-wise, $1.2 \mathrm{mmol}$ ), [Fe-cat] $(0.05 \mathrm{mmol})$, THF, $0{ }^{\circ} \mathrm{C}, 1 \mathrm{~h}$; B: CyBr $(1.0 \mathrm{mmol})$, 4 -tolyl $\mathrm{MgBr}$ $(2.0 \mathrm{mmol})$, [Fe-cat] $(0.05 \mathrm{mmol}), \mathrm{Et}_{2} \mathrm{O}, 40{ }^{\circ} \mathrm{C}, 1 \mathrm{~h} .{ }^{b}$ Conversion to 11 determined by ${ }^{1} \mathrm{H}$ NMR spectroscopy (1,3,5-trimethoxybenzene internal standard). ${ }^{c} 2.0 \mathrm{mmol} .{ }^{d} 0.1 \mathrm{mmol}$.

performance. This is despite the fact that, in all the cases examined, the pre-catalysts should be capable of providing the cis-disposed reactive sites that might be envisaged as necessary for catalytic activity if an iron-amine-based cycle such as that shown in Scheme 2 were operative.

Based on both the relative productivities of the pre-catalysts and the appearance of the reaction mixtures, it is tempting to conclude that the amine ligands do indeed dissociate from the iron centre prior to its entry into the primary catalytic cycle, as hypothesised and outlined in Scheme 3. In this scenario, amine dissociation would be triggered by reaction with excess Grignard reagent, therefore we next focussed on establishing the ease and extent of ligand dissociation from the amine complexes in the presence of a representative Grignard reagent.

\section{Reactions with benzyl Grignard reagent}

We previously found that the reaction of either $\mathrm{FeCl}_{2}$ or $\mathrm{FeCl}_{2}$ /TMEDA with excess 4-tolyl Grignard at low temperature $\left(-30{ }^{\circ} \mathrm{C}\right)$ gives species tentatively assigned as the homoleptic arylferrates $\left[\mathrm{FeAr}_{3}\right]^{-}$and $\left[\mathrm{FeAr}_{4}\right]^{2-}$ respectively, as characterised by ${ }^{1} \mathrm{H}$ NMR spectroscopy. In the latter case the TMEDA ligand is not coordinated to the paramagnetic iron centre, but instead most likely coordinates to the magnesium salt counter-ion. Whilst these species have so far proven too thermally fragile for us to isolate, we found that we were able to isolate and characterise the comparable Fe(II) benzyl-containing anionic 'ate' complex, $\left[\mathrm{FeBn}_{3}\right]^{-}(\mathbf{1 2})$, as well as the $\mathrm{Fe}(\mathrm{III})$ analogue $\left[\mathrm{FeBn}_{4}\right]^{-}(\mathbf{1 3})$, and probe its significance as a possible active intermediate in cross-coupling. ${ }^{9}$ In view of the improved stability of iron-benzyl adducts compared to iron-4-tolyl inter- 
mediates, we decided to explore the reactivity of the iron amine-complexes listed above with benzyl Grignard.

Fig. 3 shows the ${ }^{1} \mathrm{H}$ NMR spectra recorded on addition of varying amounts of $\mathrm{BnMgCl}$ to complex 6 in THF. Complex 6 is NMR silent, but the addition of one equivalent of the Grignard reagent gives a spectrum assigned as that of the complex [FeClBn(TMEDA)], 15, which could be isolated in modest yield when the reaction was repeated on a larger scale. Addition of a further 0.5 or 1 equivalent of the Grignard reagent to the NMR-scale reaction mixture led to increasing amounts of a species previously identified by Sen and co-workers as the bisbenzyl complex 14a. ${ }^{16}$ As described previously, ${ }^{9}$ the addition of excess $\mathrm{BnMgCl}$ rapidly led to the formation of the 'ate' complex 12.


As yet, no structural evidence has been provided for 14a, however Chirik and co-workers have reported the crystal structure of the equivalent sparteine-based analogue, $14 \mathbf{b} .{ }^{12}$ The ${ }^{1} \mathrm{H}$ NMR spectrum of $\mathbf{1 4 b}$, formed in situ from 7 and two equivalents of benzyl Grignard, is shown in Fig. 4(a). Addition of excess (20 equivalents) of Grignard again led to the formation of the anionic complex 12, but the reaction is significantly slower than with the Fe-TMEDA mixture, presumably as a function of increased chelate complex stability with the more conformationally constrained sparteine ligand.

The ${ }^{1} \mathrm{H}$ NMR spectrum of the HMTETA-containing complex 8 in THF at room temperature is shown in Fig. 5(a), whilst (b) shows the spectrum after addition of 2 equivalents of $\mathrm{BnMgCl}$. The latter spectrum is more complicated and is likely to correspond to the formation of one or more iron-benzyl/HMTETA adducts. On addition of a further two equivalents of the



Fig. 3 (a) ${ }^{1}$ H NMR spectrum of complex 6 in THF (NMR silent). (b) Part of spectrum of complex 15, formed in situ from 6 and 1 equiv. $\mathrm{BnMgCl} / \mathrm{Fe}$ (peak at $1067 \mathrm{ppm}$ omitted). (c) and (d) Addition of a further 0.5 and 1 equivalent of $\mathrm{BnMgCl} / \mathrm{Fe}$. Peaks marked ' $*$ ' correspond to [FeBn $\left.{ }_{2}(\mathrm{TMEDA})\right]$, (14a).

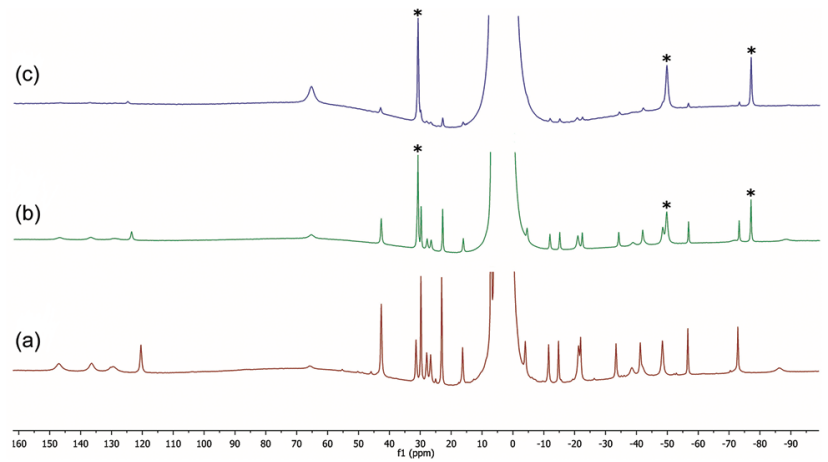

Fig. 4 (a) ${ }^{1} \mathrm{H}$ NMR spectrum of complex $14 \mathrm{~b}$ in THF. (b) $14 \mathrm{~b}+20$ $\mathrm{BnMgCl}$, after $10 \mathrm{~min}$. (c) As above, after $5 \mathrm{~h}$; peaks marked with ' $*$ ' correspond to 'ate' complex 12.

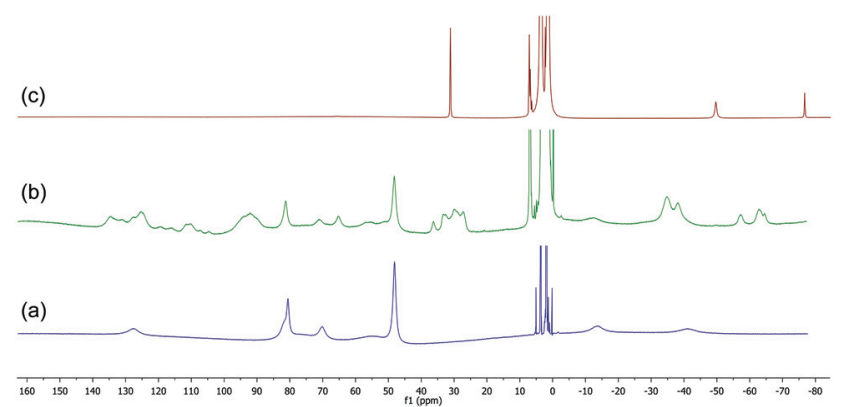

Fig. 5 (a) ${ }^{1} \mathrm{H}$ NMR spectrum of complex 8. (b) and (c) Spectra recorded after addition of 2 and 4 equiv. $\mathrm{BnMgCl}$ respectively.

Grignard reagent, the tetraamine ligand was lost from the iron centre and the 'ate' complex $\mathbf{1 2}$ was once again the only paramagnetic iron-containing complex observed (spectrum (c)). The data clearly show that, as with both the TMEDA- and sparteinecontaining complexes, the presence of excess Grignard reagent favours the dissociation of HMTETA and the concomitant formation of the amine-ligand-free homoleptic 'ate' complex 12.

The ${ }^{1} \mathrm{H}$ spectra of macrocyclic complexes $\mathbf{9}$ and $\mathbf{1 0}$ are shown in Fig. 6 (spectra (a) and (c) respectively), meanwhile

(d)

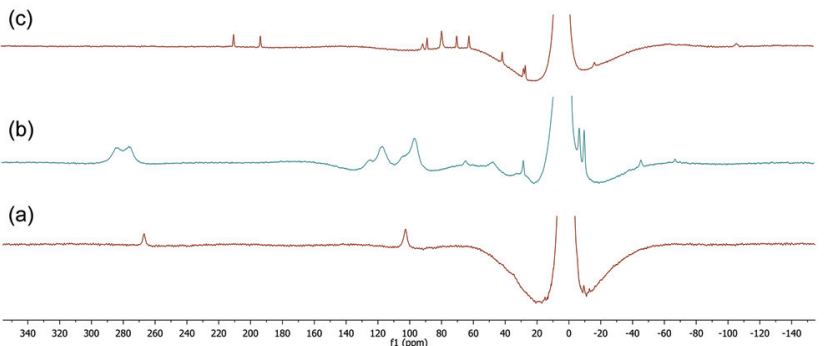

Fig. 6 (a) and (c) ${ }^{1} \mathrm{H}$ NMR spectra of complexes 9 and 10 respectively (THF, r.t.); (b) and (d) spectra recorded 10 minutes after addition of 10 equiv. $\mathrm{BnMgCl}$ to 9 and 10 respectively. 
the spectra of the red and orange reaction mixtures recorded 10 minutes after addition of excess $\mathrm{BnMgCl}$ (10 equivalents) to $\mathbf{9}$ and $\mathbf{1 0}$ are shown in plots (b) and (d) respectively. It is clear that new paramagnetic complexes were formed in both cases, again presumably containing benzyl ligands in addition to the macrocyclic amine ligands. However, in stark contrast to all of the reactions discussed above with iron complexes of TMEDA, sparteine or HMTETA, none of the homoleptic anionic complex 12 was observed suggesting that the macrocyclic ligands were not displaced by the Grignard reagent. Indeed, no 12 was observed when the spectra were run again after 24 hours.

\section{Conclusions}

The lability of the amine ligands of the complexes 5-10 in the presence of excess benzyl Grignard reflects decreasing catalytic activity in the coupling of cyclohexylbromide with 4-tolylmagnesium bromide, with the least labile systems showing the poorest catalytic activity. Of particular note, whilst the complexes $\mathbf{9}$ and $\mathbf{1 0}$ do react with benzyl Grignard, the amine ligands are not displaced by excess Grignard, unlike the amine ligands in the other complexes examined. These two complexes show only very poor activity as catalysts in the crosscoupling reactions and it is important to note that in these cases the reaction mixtures stay homogeneous throughout the catalysis. Conversely TMEDA, sparteine and HMTETA are all displaceable by excess benzyl Grignard, and their complexes are catalytically competent with an activity in the order HMTETA < sparteine < TMEDA reflecting the decreasing chelate effect of the ligands. In these cases the catalytic reactions all turned black, suggestive of the formation of iron nanoparticles.

Taken together the data reported here provide further strong evidence that amine ligands are not coordinated to the iron centre in the primary catalytic cycle of Kumada reactions employing iron-amine pre-catalysts, lending support to variants of the catalytic cycle outlined in Scheme 3.

\section{Experimental}

\section{General}

All reactions were carried out under a dry atmosphere of nitrogen using standard Schlenk line and glove box techniques, unless otherwise specified. Anhydrous solvents were obtained from a Grubbs solvent drying system, degassed and stored over molecular sieves in a flame dried Strauss flask. Commercial reagents were used as received without further purification unless otherwise specified. The ligand $\mathrm{Me}_{2} \mathrm{EBC}$ was prepared according to a literature method. ${ }^{17}{ }^{1} \mathrm{H}$ NMR spectra were recorded on a Jeol Lambda 300, Jeol ECP 400, Varian 400-MR, or Varian 500 spectrometer. Half-height peak widths for paramagnetic compounds are reported in $\mathrm{Hz}$ in parentheses after the chemical shift. Elemental analyses were obtained from the microanalytical service at the University of Bristol. Infrared spectra were recorded on a PerkinElmer Spectrum 100 FTIR Spectrometer, selected frequencies are reported.

Preparation of $\left[\{\mathbf{F e C l}(\boldsymbol{\mu}-\mathrm{Cl})(\mathrm{TMEDA})\}_{2}\right], 6$. Prepared following a literature procedure. ${ }^{11} \mathrm{FeCl}_{2}(4.10 \mathrm{~g}, 32.3 \mathrm{mmol})$ and TMEDA (4.90 $\mathrm{ml}, 32.7 \mathrm{mmol})$ were heated for $1 \mathrm{~h}$ in THF $(150 \mathrm{ml})$ at reflux temperature. After cooling, the volume was reduced by a third and the mixture cooled to $-20{ }^{\circ} \mathrm{C}$ to give a crop of crystals of 6 (3.72 g, 47.4\%). Anal. Found: C, 30.10; H, 6.92; N, 11.20. Calcd for $\mathrm{C}_{12} \mathrm{H}_{32} \mathrm{Cl}_{4} \mathrm{Fe}_{2} \mathrm{~N}_{4}$ : C, 29.66; $\mathrm{H}, 6.64 ; \mathrm{N}, 11.53$.

Preparation of $\left[\mathrm{FeCl}_{2}((-)\right.$-sparteine $\left.)\right]$, 7. A literature preparation was followed. ${ }^{12}$ To a mixture of $\mathrm{FeCl}_{2}(1.09 \mathrm{~g}$, $8.60 \mathrm{mmol})$ in THF (5 ml) was added a solution of (-)-sparteine $(2.02 \mathrm{~g}, 8.60 \mathrm{mmol})$ in THF $(2 \mathrm{ml})$ and the reaction mixture stirred for $18 \mathrm{~h}$ to give a suspension. The white solid was isolated by filtration, washed with diethyl ether and dried under reduced pressure to yield 7 (2.61 g, 83.9\%). The ${ }^{1} \mathrm{H}$ NMR spectroscopic data $\left(\mathrm{CDCl}_{3}\right)$ were in agreement with reported values. ${ }^{12}{ }^{1} \mathrm{H}$ NMR $\left(400 \mathrm{MHz}, 25.0{ }^{\circ} \mathrm{C}\right.$, THF) $\delta 352.3(271,1 \mathrm{H})$, 313.5 (296, 1H), 297.1 (275, 1H), 175.9 (167, 1H), 139.2 (632, $2 \mathrm{H}), 118.3(821,1 \mathrm{H}), 43.3(79,1 \mathrm{H}), 41.8(74,1 \mathrm{H}), 37.5(56,1 \mathrm{H})$, $24.5(106,1 \mathrm{H}), 22.9(94,1 \mathrm{H}), 10.9(65,1 \mathrm{H}), 7.2(30,1 \mathrm{H}),-6.6$ $(42,1 \mathrm{H}),-7.2(53,1 \mathrm{H}),-15.1(83,1 \mathrm{H}),-15.6(59,1 \mathrm{H}),-22.0$ $(68,2 \mathrm{H}),-34.3(69,2 \mathrm{H}),-38.0(766,1 \mathrm{H}),-44.6(81,1 \mathrm{H}),-69.6$ (797, 1H), -134.4 (970, 1H). Anal. Found: C, 49.62; H, 6.91; N, 7.73. Calcd for $\mathrm{C}_{15} \mathrm{H}_{26} \mathrm{Cl}_{2} \mathrm{FeN}_{2}$ : C, 49.89; H, 7.26; N, 7.76.

Preparation of cis-[ $\mathbf{F e C l}_{2}$ (HMTETA)], 8. A flame dried Schlenk was charged with $\mathrm{FeCl}_{2}(1.52 \mathrm{~g}, 12.0 \mathrm{mmol})$ and THF $(20 \mathrm{ml})$ and the mixture was stirred for $10 \mathrm{~min}$ to give a grey/pink suspension. HMTETA was added in one portion $(3.26 \mathrm{ml}$, $12.0 \mathrm{mmol}$ ), the reaction mixture stirred for $30 \mathrm{~min}$ at room temperature and then heated at reflux for $8 \mathrm{~h}$, after which time it was allowed to cool and the supernatant removed via a filter cannula. The remaining fine solid was washed with cold THF $(3 \times 3 \mathrm{ml})$ and then dried under vacuum to give 8 as a white solid (3.45 g, 80.5\%). ${ }^{1} \mathrm{H}$ NMR (400 MHz, 25.0 ${ }^{\circ} \mathrm{C}$, THF) $\delta 127.6$ (1471), 81.6 (942), 80.5 (372), 70.1 (854), 55.0 (3314), 48.1 (403), -13.6 (1605), -41.1 (2143). Anal. Found: C, 40.02; H, 8.51; N, 15.56. Calcd for $\mathrm{C}_{12} \mathrm{H}_{30} \mathrm{Cl}_{2} \mathrm{FeN}_{4}$ : C, 40.36; $\mathrm{H}, 8.47 ; \mathrm{N}, 15.64$. Crystals suitable for X-ray structure determination were grown from a THF solution. IR ( $\left.\mathrm{cm}^{-1}\right): 2972 \mathrm{w}, 2859 \mathrm{~m}, 2824 \mathrm{~m}, 1468$ sh, 1446 sh, 1281 sh, 1174 w, 1138 w, 1116 m, 1066 m, 1057 m, 1031 sh, 1010 m, 984 sh, 935 sh, 897 sh, 794 m, 780 sh, 604 m, $576 \mathrm{~m}$.

Preparation of [FeCl(TMC)]Cl, 9. A Schlenk was charged with tetramethylcyclam $(111 \mathrm{mg}, 0.43 \mathrm{mmol})$ and anhydrous MeCN (5 ml). $\mathrm{FeCl}_{2}$ was added in one portion (55 $\mathrm{mg}, 0.43 \mathrm{mmol}$ ) and the reaction mixture stirred for $30 \mathrm{~min}$ at room temperature. The reaction mixture was then heated at $40{ }^{\circ} \mathrm{C}$ for $1 \mathrm{~h}$ resulting in a pale yellow solution, which was allowed to cool, filtered via cannula and left at $-20^{\circ} \mathrm{C}$ to give a crop of crystals suitable for X-ray structure determination. The crystals were washed with cold THF ( $2 \mathrm{ml}$ ) and dried under vacuum to give the product as a colourless solid $(107 \mathrm{mg}, 64.9 \%) .{ }^{1} \mathrm{H}$ NMR (400 MHz, $\left.25.0{ }^{\circ} \mathrm{C}, \mathrm{THF}\right): \delta=265.9$ (589), 103.2 (952). Anal. Found: C, 43.99; H, 8.19; N, 14.24. Calcd for $\mathrm{C}_{14} \mathrm{H}_{32} \mathrm{Cl}_{2} \mathrm{FeN}_{4}$ : C, 
43.88; H, 8.42; N, 14.62. IR ( $\left.\mathrm{cm}^{-1}\right): 2865$ br, $1472 \mathrm{sh}, 1458 \mathrm{sh}$, 1426 w, 1115 sh, 1067 sh, 999 sh, 963 sh, 930 w, 804 sh, $727 \mathrm{sh}$.

Preparation of $\left[\mathrm{FeCl}_{2}\left(\mathrm{Me}_{2} \mathrm{EBC}\right)\right]$, 10. A literature procedure was followed. ${ }^{13}$ A solution of $\mathrm{Me}_{2} \mathrm{EBC}(1.02 \mathrm{~g}, 4.0 \mathrm{mmol})$ in anhydrous acetonitrile $(20 \mathrm{ml})$ was added to a suspension of $\left[\mathrm{FeCl}_{2}(\mathrm{py})_{2}\right](1.14 \mathrm{~g}, 4.0 \mathrm{mmol})$ in anhydrous acetonitrile and the mixture stirred for $16 \mathrm{~h}$ at room temperature. (Note: all sources of adventitious water must be avoided as water coordinates preferentially in the ligand cavity and cannot be displaced by the iron.) The reaction mixture was filtered and the solvent removed from the filtrate under reduced pressure to give the product as a light brown solid (1.35 g, 88.5\%). ${ }^{1} \mathrm{H}$ NMR (400 MHz, $\left.25.0{ }^{\circ} \mathrm{C}, \mathrm{THF}\right): \delta=209.5$ (234), 192.7 (234), 90.7 (411), 88.0 (248), 78.8 (453), 69.2 (248), 61.6 (218), 40.7 (262), 27.3 (290), 26.3 (276), -17.2 (397), -106.6 (893). Anal. Found: C, 45.36; H, 8.25; N, 15.14. Calcd for $\mathrm{C}_{14} \mathrm{H}_{30} \mathrm{Cl}_{2} \mathrm{FeN}_{4}$ : C, 45.11; H, 7.93; N, 14.70. Crystals suitable for X-ray structure determination were grown from a cooled THF solution.

\section{Cross-coupling of 4-tolylMgBr with cyclohexyl bromide Table 1, conditions A}

Cyclohexyl bromide (123 $\mu \mathrm{l}, 1.0 \mathrm{mmol})$, the appropriate iron complex $(0.05 \mathrm{mmol})$ and where appropriate, TMEDA (300 $\mu \mathrm{l}$, $2.0 \mathrm{mmol})$ were stirred for 3 minutes in THF $(2.0 \mathrm{ml})$ held at $0{ }^{\circ} \mathrm{C}$. 4-TolylMgBr (1.2 mmol) was added dropwise with stirring over 30 min using a syringe pump and the reaction mixture was stirred for a further $30 \mathrm{~min}$ at $0{ }^{\circ} \mathrm{C}$. The reaction was quenched by addition of $\mathrm{H}_{2} \mathrm{O}(5 \mathrm{ml})$ and the organic products extracted with $\mathrm{CH}_{2} \mathrm{Cl}_{2}(3 \times 10 \mathrm{ml})$. 1,3,5-Trimethoxybenzene (168 mg, $1.0 \mathrm{mmol}$ ) was added as an internal standard and the conversion to cross-coupled product was determined by ${ }^{1} \mathrm{H}$ NMR spectroscopy. Conditions B. Cyclohexyl bromide $(123 \mu \mathrm{l}$, $1.0 \mathrm{mmol})$, the relevant iron complex $(0.05 \mathrm{mmol})$ and where appropriate, TMEDA (15 $\mu \mathrm{l}, 0.1 \mathrm{mmol})$ were stirred for 3 minutes in $\mathrm{Et}_{2} \mathrm{O}(3.0 \mathrm{ml})$ at room temperature. 4-TolylMgBr $(2.0 \mathrm{mmol})$ was added in one portion and the reaction mixture heated at reflux temperature for $1 \mathrm{~h}$. Workup and determination of conversion to cross-coupled product as above.

\section{NMR studies of the reaction of iron-amine chelate complexes with BnMgCl (Fig. 3-6)}

The appropriate iron-amine complex $(0.5 \mathrm{mmol})$ was dissolved in THF ( $2 \mathrm{ml})$, BnMgCl (0.84 $\mathrm{M}$ in THF, specified amount) was added at room temperature, the reaction mixture stirred for $10 \mathrm{~min}$, a sample was removed and the ${ }^{1} \mathrm{H}$ NMR was recorded.

\section{Preparation of [FeClBn(TMEDA)], 15}

Complex 6 (0.972 g, $2.0 \mathrm{mmol})$ was dissolved in THF $(5.0 \mathrm{ml})$, $\mathrm{BnMgCl}$ added $(2.0 \mathrm{ml}, 2.0 \mathrm{M}$ in THF, $4.0 \mathrm{mmol}$ ) and the reaction mixture stirred for $10 \mathrm{~min}$ to give an orange solution. Cooling the solution at $-20{ }^{\circ} \mathrm{C}$ gave $\mathbf{1 5}$ as an orange solid (402 mg, 33.7\%). ${ }^{1} \mathrm{H}$ NMR (400 MHz, $25.0{ }^{\circ} \mathrm{C}$, THF) $\delta 1066.8$ (3823 Hz, 4H), 121.6 (2168), 102.7 (892), 99.4 (763), 93.3 (688), 88.1 (1897), $30.4(73,4 \mathrm{H}),-36.3(337,4 \mathrm{H}),-61.9(76,2 \mathrm{H})$.
Anal. Found: C, 52.58; H, 8.02; N, 8.95. Calcd for $\mathrm{C}_{26} \mathrm{H}_{46} \mathrm{Cl}_{2} \mathrm{Fe}_{2} \mathrm{~N}_{4}$ : C, 52.28; H, 7.76; N, 9.38.

\section{Preparation of $\left[\mathrm{FeBn}_{2}((-)\right.$-sparteine $\left.)\right], 14 \mathrm{~b}$}

A literature preparation was followed. ${ }^{12}$ To $7(0.203 \mathrm{~g}$, $0.562 \mathrm{mmol})$ was added diethyl ether $(5 \mathrm{ml})$ and the mixture stirred. To this was added $\mathrm{KCH}_{2} \mathrm{C}_{6} \mathrm{H}_{5}(0.146 \mathrm{~g}, 1.12 \mathrm{mmol})$ in diethyl ether $(10 \mathrm{ml})$ and the reaction mixture was stirred for $6 \mathrm{~h}$ to give a yellow solution. This was filtered through celite and the solvent removed in vacuo to yield $\mathbf{1 4 b}$ as a yellow solid (0.151 g, 57.1\%). The ${ }^{1} \mathrm{H}$ NMR spectroscopic data (benzene- $\mathrm{d}_{6}$ ) were in agreement with reported values, ${ }^{12}$ and were also recorded in THF. ${ }^{1} \mathrm{H}$ NMR (400 $\mathrm{MHz}, 25.0{ }^{\circ} \mathrm{C}$, THF) $\delta 932.8$ (2433, 1H), 896.2 (2107, 1H), 827.8 (2401, 1H), 777.7 (1626, 1H), 350.9 (343, 1H), $341.2(371,1 \mathrm{H}), 218.9(315,1 \mathrm{H}), 147.3$ (958, 1H), 136.8 (794, 1H), $129.6(1203,1 \mathrm{H}), 120.8(215,1 \mathrm{H})$, $43.2(135,2 \mathrm{H}), 31.7(134,1 \mathrm{H}), 29.9(99,2 \mathrm{H}), 28.4(168,1 \mathrm{H})$, 27.1 (187, 1H), $23.1(103,2 \mathrm{H}), 16.7(150,1 \mathrm{H}), 7.1$ (93, 1H), 6.0 $(105,1 \mathrm{H}),-3.6(177,1 \mathrm{H}),-11.3(134,1 \mathrm{H}),-14.6(122,1 \mathrm{H})$, $-21.4(311,1 \mathrm{H}),-21.8(161,1 \mathrm{H}),-33.3(137,1 \mathrm{H}),-38.3(575$, $1 \mathrm{H}),-41.0(165,1 \mathrm{H}),-41.8(649,1 \mathrm{H}),-48.3(277,1 \mathrm{H}),-56.7$ $(87,1 \mathrm{H}),-72.9(104,2 \mathrm{H}),-86.0(1139,1 \mathrm{H}),-148.1(1208,1 \mathrm{H})$.

\section{Acknowledgements}

We thank the EPSRC for a PhD studentship (JN) and postdoctoral support (PBB and DE, grant number EP/K012258/1).

\section{Notes and references}

1 (a) Metal-Catalyzed Cross-Coupling Reactions, ed. A. de Meijere and F. Diederic, Wiley-VCH, 2nd edn, 2008; (b) Handbook of Organopalladium Chemistry for Organic Synthesis, ed. E. Negishi, Wiley, 2002.

2 M. Albrecht, R. Bedford and B. Plietker, Organometallics, 2014, 33, 5619.

3 It should be noted that iron-catalysed cross-couplings predate analogous palladium-catalysed processes. For seminal examples see: (a) G. Vavon and P. Mottez, C. R. Hebd. Seances Acad. Sci., 1944, 218, 557; (b) W. C. Percival, R. B. Wagner and N. C. Cook, J. Am. Chem. Soc., 1953, 75, 3731; (c) M. Tamura and J. K. Kochi, J. Am. Chem. Soc., 1971, 93, 1487; (d) M. Tamura and J. Kochi, Synthesis, 1971, 303; (e) S. M. Neumann and J. K. Kochi, J. Org. Chem., 1975, 40, 599; (f) R. S. Smith and J. K. Kochi, J. Org. Chem., 1976, 41, 502.

4 Recent reviews: (a) I. Bauer and H.-J. Knölker, Chem. Rev., 2015, 115, 3170; (b) R. B. Bedford and P. B. Brenner, Top. Organomet. Chem., 2015, 50, 19; (c) E. Nakamura, T. Hatakeyama, S. Ito, K. Ishizuka, L. Ilies and M. Nakamura, Org. React., 2014, 83, 1.

5 M. Nakamura, K. Matsuo, S. Ito and E. Nakamura, J. Am. Chem. Soc., 2004, 126, 3686. 
6 R. B. Bedford, D. W. Bruce, R. M. Frost and M. Hird, Chem. Commun., 2005, 4161.

7 G. Cahiez, V. Habiak, C. Duplais and A. Moyeux, Angew. Chem., Int. Ed., 2007, 46, 4364.

8 D. Noda, Y. Sunada, T. Hatakeyama, M. Nakamura and H. Nagashima, J. Am. Chem. Soc., 2009, 131, 6078.

9 R. B. Bedford, P. B. Brenner, E. Carter, P. M. Cogswell, M. F. Haddow, J. N. Harvey, D. M. Murphy, J. Nunn and C. H. Woodall, Angew. Chem., Int. Ed., 2014, 53, 1804.

10 R. B. Bedford, Acc. Chem. Res., 2015, 48, 1485.

11 S. C. Davies, D. L. Hughes, G. J. Leigh, J. R. Sanders and J. S. de Souza, J. Chem. Soc., Dalton Trans., 1997, 1981.

12 S. C. Bart, E. J. Hawrelak, A. K. Schmisseur, E. Lobkovsky and P. J. Chirik, Organometallics, 2004, 23, 237.
13 T. J. Hubin, J. M. McCormick, S. R. Collinson, M. Buchalova, C. M. Perkins, N. W. Alcock, P. K. Kahol, A. Raghunathan and D. H. Busch, J. Am. Chem. Soc., 2000, 122, 2512.

14 R. B. Bedford, M. Betham, D. W. Bruce, S. A. Davis, R. M. Frost and M. Hird, Chem. Commun., 2006, 1398.

15 R. B. Bedford, P. B. Brenner, E. Carter, T. W. Carvell, P. M. Cogswell, T. Gallagher, J. N. Harvey, D. M. Murphy, E. C. Neeve, J. Nunn and D. R. Pye, Chem. - Eur. J., 2014, 20, 7935.

16 D. H. Hill and A. Sen, J. Am. Chem. Soc., 1988, 110, 1650.

17 E. H. Wong, G. R. Weisman, D. C. Hill, D. P. Reed, M. E. Rogers, J. S. Condon, M. A. Fagan, J. C. Calabrese, K. Lam, I. A. Guzei and A. L. Rheingold, J. Am. Chem. Soc., 2000, 122, 10561. 